\title{
The reform patient information sheet sub study - an embedded trial evaluating the enhancement of patient information sheets to improve recruitment
}

\author{
Sarah Cockayne ${ }^{1 *}$, Joy Adamson ${ }^{1}$, Peter Bower ${ }^{2}$, Belen Corbacho ${ }^{1}$, Caroline Fairhurst', Lisa Farndon ${ }^{8}$, Kate Hicks ${ }^{1}$, \\ Anne-Maree Keenan ${ }^{3,4}$, Peter Knapp ${ }^{1}$, Sally Lamb ${ }^{5}$, Lorraine Loughrey ${ }^{3,4}$, Caroline Mclntosh ${ }^{6}$, Hylton Menz ${ }^{7}$, \\ Anthony Redmond ${ }^{3,4}$, Jo Rick' , Sara Rodgers ${ }^{1}$, Wesley Vernon ${ }^{8}$, Jude Watson ${ }^{1}$, David Torgerson ${ }^{1}$
}

From 3rd International Clinical Trials Methodology Conference

Glasgow, UK. 16-17 November 2015

During recruitment, potential trial participants are usually given a written study patient information sheet (PIS). These are often long, complex and visually unappealing documents, which may have a negative impact on recruitment. Improving their readability by employing user testing, and their presentation by using graphic designers may improve patient understanding and aid recruitment.

We undertook an embedded randomised controlled trial within the NIHR-funded REFORM study, as part of the MRC START initiative, to evaluate whether enhancing PIS improves trial recruitment and retention. 6,900 patients due to be mailed a REFORM recruitment pack were randomised in a 1:1:1 ratio to receive one of three types of PIS: the original based on the NHS ethics template $(n=2,298)$; an enhanced, user tested PIS $(n=2,301)$; or a 'template' PIS which was developed using an enhanced PIS from another trial in a similar population $(\mathrm{n}=2,301)$.

193 participants $(2.8 \%)$ were randomised to the trial: 62 $(2.7 \%)$ in the control group; $63(2.7 \%)$ in the user tested group; and $68(3.0 \%)$ in the template group (OR: template vs control 1.10 (95\% CI 0.77-1.56, $\mathrm{p}=60)$ ) user tested vs control 1.01 (95\% CI 0.71-1.45, $\mathrm{p}=0.94$ ); and user tested vs template $0.92(95 \% \mathrm{CI} 0.65-1.31, \mathrm{p}=0.65))$. Logistic regression analysis demonstrated that PIS allocation did not significantly predict recruitment $(\mathrm{p}=0.33)$ or retention in the trial $(\mathrm{p}=0.83)$.

There was no evidence to suggest that enhanced PIS increased recruitment and retention rates to the REFORM

${ }^{1}$ University of York, York, UK

Full list of author information is available at the end of the article trial. However, the number of patients randomised was low and we may be underpowered to detect a difference.

\section{Authors' details}

'University of York, York, UK. ${ }^{2}$ The University of Manchester, Manchester, UK. ${ }^{3} \mathrm{NIHR}$ Leeds Musculoskeletal Biomedical Research Unit, Leeds, UK. ${ }^{4}$ Leeds Institute of Rheumatic and Musculoskeletal Medicine, Leeds, UK. ${ }^{5}$ University of Oxford, Oxford, UK. ${ }^{6} \mathrm{NUI}$ Galway, Galway, Ireland. ${ }^{7}$ La Trobe University, Bundoora, Australia. ${ }^{8}$ Sheffield Teaching Hospitals, Sheffield, UK.

Published: 16 November 2015

\section{doi:10.1186/1745-6215-16-S2-P87}

Cite this article as: Cockayne et al:: The reform patient information sheet sub study - an embedded trial evaluating the enhancement of patient information sheets to improve recruitment. Trials 2015 16(Suppl 2):P87.

Submit your next manuscript to BioMed Central and take full advantage of:

- Convenient online submission

- Thorough peer review

- No space constraints or color figure charges

- Immediate publication on acceptance

- Inclusion in PubMed, CAS, Scopus and Google Scholar

- Research which is freely available for redistribution 